\title{
SYNTHESIS OF WOUND-HEALING KERATIN HYDROGELS USING CHICKEN FEATHERS PROTEINS AND ITS PROPERTIES
}

\author{
PRIYAAH KUMARAN ${ }^{1}$, ARUN GUPTA ${ }^{1,2 *}$, SWATI SHARMA ${ }^{1 *}$ \\ 1Faculty of Chemical and Natural Resources Engineering, Universiti Malaysia Pahang, 26300 Pahang, Malaysia, ${ }^{2}$ Centre for Biocomposite \\ and Innovative Materials (CBIM) Universiti Malaysia Pahang, 26300 Pahang, Malaysia \\ Email: arungupta10@gmail.com, sspandit.89@gmail.com \\ Received: 11 Oct 2016 Revised and Accepted: 21 Dec 2016
}

\section{ABSTRACT}

Objective: A novel cross-linked keratin hydrogel was prepared by integrating keratin from chicken feather into an aloe-vera, Chitosan and honey based dressing formulation separately.

Methods: Keratin fibres extracted from chicken feathers are eco-friendly, non-abrasive, biodegradable, insoluble in organic solvents and having good mechanical properties, hydrophobic behaviour, low density and finally cheap. Keratin based hydrogels were prepared with five types of ingredients and studied for their wound healing properties. The analysis of keratin-based hydrogel was done by Fourier Transform Infra-red Spectroscopy (FTIR) and X-ray diffraction (XRD) analysis.

Results: Keratinocytes containing keratin travel from the wound border to initiate the process of healing. The characteristics of keratin-based hydrogel derived from chicken feather made it an effective wound care therapeutic product. X-ray diffraction (XRD) analysis showed the crystallinity index in between $30-50 \%$ of the hydrogen.

Conclusion: The test for swelling and solubility were carried out on the hydrogen to determine the solid content and water absorbance capacity. Overall, this product is safe to use as an effective wound healing product with appropriate properties.

Keywords: Chicken feathers, Keratin, Eco-friendly, Hydrogel, Wound healing, FTIR

(C) 2017 The Authors. Published by Innovare Academic Sciences Pvt Ltd. This is an open access article under the CC BY license (http://creativecommons.org/licenses/by/4. 0/) DOI: http://dx.doi.org/10.22159/ijpps.2017v9i2.15620

\section{INTRODUCTION}

Recently, many therapeutic products were developed by pharmaceutical industries for wound healing and to enhance recovery of major injuries. Among these, hydrogels are polymeric materials which can absorb and hold a greater amount of water [1]. They are characterised by hydrophobicity and are not dissolved in water [2]. Usage of biomaterials in these products increased rapidly due to the establishment of a matrix or scaffolding system that reproduce the structure and function of the indigenous tissue. There are many applications of keratins in protein-based biomaterials, biomedical and pharmaceutical sectors [3, 4]. This is mainly, because of their ability to work as an extracellular matrix that facilitates cell-matrix and cell-cell interactions. The protein components contained a defined, three-dimensional microstructure that aids in cellular proliferation and cell-guided tissue formation, which are essential characteristics for biomaterial scaffolds. In addition, the strong bioactivities and diverse physiochemical properties of proteinaceous macromolecules are attractive for other biomedical applications such as medical devices, bioactive surfaces, hygienic products, etc. Keratin-based materials have shown promise to revolutionise the biomaterial world due to their intrinsic biocompatibility, biodegradability, mechanical durability and natural abundance [5].

Sometimes the wounds on human's skin could not be treated well and cause severe infections. To assess the wound and identify the correct treatment, patients' body condition is essential to consider [6]. When assessing the wound, the first step is to determine the aetiology of the wound. Recognising the factors that affects patient's ability to heal determines the right treatment and overcome the slow and incomplete healing [7]. Different types of wounds need specific treatment and dressing according to the conditions [8]. The biocompatible keratin hydrogel can be used as a component in wound care and dressings. Hydrogels play an important role in controlling the wound environment and providing a suitable medium for the delivery of biomolecules to stimulate or assist healing. In addition, keratin materials derived from the SFK inhibitor fusion protein (SIFP) protein fraction contain a high amount of sulphide groups which help to absorb the moisture. The keratin composed of structural proteins and in combination with natural products, these become more effective to absorb the moisture or wound exudates [9]. The polymeric material is a necessary aspect for tissue healing in tissue engineering. The proteinaceous polymeric hydrogels have a minimum inflammatory response. However, use of natural material instead of synthetic polymer to make hydrogel is a challenge.

Chicken feathers are abundantly available as poultry waste. Thus it becomes another advantage to produce the environmentally friendly product. Feather keratins have strong potential to make clinically important biomaterials and have a great tendency to make hydrogel by polymerise in aqueous surroundings. To promote the healing process, aloe-vera, chitosan, and honey are included in the formulation due to their healing property [10]. Chitosan is non-toxic and non-allergic, and its biocompatibility, biodegradability and bioactivity made it a very attractive component for pharmaceutical and medical fields [11]. Honey is a standout among the most continuing materials utilised as a part of wound care, credited to its antibacterial, calming and cancer prevention agent properties [12]. Aloe vera gel has been used throughout history for its therapeutic healing effect on burns, insect bites and other skin injuries [13].

In the present work, keratin is extracted from chicken feather by chemical treatment [14]. The extracted keratin was used to synthesise the hydrogel for wound healing application due to its polymerizing properties. To check the properties of made hydrogel, it was characterised by using Fourier Transform Infrared Spectroscopy (FTIR), X-ray diffraction (XRD), swelling capacity and solubilising capability under standard conditions. This study provides an interesting platform to synthesize the value added products from the waste biomass of chicken feathers in an ecofriendly manner. It also directed the bioremediations of huge poultry waste and synthesis of other useful products. 


\section{MATERIALS AND METHODS}

\section{Chemicals}

Chemicals were obtained from two sources, namely RandM chemicals, Kuala Lumpur, Malaysia (polyvinyl pyrrolidone, chitosan and polyvinyl alcohol) and Sigma-Aldrich, Kuala Lumpur, Malaysia (glutaraldehyde 50\% and polyethene glycol). Aloe-vera gel (purity 99\%) was purchased from an Amway shop in Kuantan, Malaysia.

\section{Preparation of hydrogel}

Keratin solution was prepared in the chemical engineering lab at Universiti Malaysia Pahang as discussed in our previous studies [15]. The chemicals used in the formulation is given in table 1.

Hydrogel was prepared by dissolving $3 \mathrm{~g}$ of polyvinyl alcohol (PVA; $20 \%$ ) and $2 \mathrm{~g}$ of polyvinyl pyrrolidone (PVP; $10 \%$ ) with $4 \mathrm{~g}$ of keratin solution and $1 \mathrm{~g}$ of polyethene glycol in $100 \mathrm{ml}$ of $\mathrm{ddH}_{2} \mathrm{O}$, at $60^{\circ} \mathrm{C}$ under continuous stirring. The mixed solution was then poured in the petri plates and solidified by freezing-thawing repetitive cycles. All tests were done in three duplicates $(n=3)$, where normal mean esteem and standard deviation (SD) were plotted. The resulting hydrogel is then washed with $\mathrm{ddH}_{2} \mathrm{O}$ three times to remove any unreacted keratin and polymers. For other formulations, the aloe-vera gel, chitosan solution and honey were added to the mixture using the same method. The solution was stirred for about 15 min to mix uniformly.

The hydrogel having different compositions were named as hydrogel control (hydrogel C), PPG hydrogel (Polypropylene Glycol (PPG), Honey+Polyethylene Glycol (PEG) (H-PEG hydrogel), Chitosan+PEG (CPEG hydrogel), Aloe-vera+PPG hydrogel (A-PPG hydrogel), Aloevera+PPG (A-PPG' hydrogel) having different concentrations from the last composition. Acidity/alkalinity $(\mathrm{pH})$ test was performed with fluid concentrates of the hydrogel.

Table 1: Composition and different hydrogel formulations

\begin{tabular}{llllll}
\hline Compositions & \multicolumn{2}{l}{ Formulations (w/w \%) } & & \\
\cline { 2 - 6 } & PPG hydrogel & H-PEG hydrogel & C-PEG hydrogel & A-PPG hydrogel & A-PPG' hydrogel \\
\hline PVA & 35 & 30 & 30 & 30 & 30 \\
PVP & 25 & 20 & 20 & 20 & 20 \\
Keratin & 30 & 30 & 30 & 30 & 30 \\
Honey & - & - & 10 & - & 7.5 \\
Chitosan & - & - & - & 10 & 7.5 \\
Aloe Vera & - & - & - & 10 & 5 \\
PPG & 10 & 10 & 10 & - & - \\
PEG & - & & & & \\
\end{tabular}

Abbreviation: PPG, Polypropylene Glycol; PEG, Polyethylene Glycol; PVP, Polyvinyl Pyrrolidone; H-PEG, Honey+Polyethylene Glycol; C-PEG, Chitosan+PEG; A-PPG, Aloe-vera+PPG; A-PPG', Aloe-vera+PPG (last two are different in concentration).

\section{Analysis of swelling test}

The swelling was measured by using Japanese Industrial Standard (JIS) K7223. The dry gel was submerged in deionized water for $16 \mathrm{~h}$ at room temperature. In the beginning of swelling, the hydrogel was shifted to a stainless-steel net of 100 -work $(149 \mu \mathrm{m})$. Swelling is computed as takes after [16].

$$
\text { Swelling }=\frac{C}{B} * 100
$$

Where $\mathrm{C}$ is the weight of hydrogel got in the wake of drying and $\mathrm{B}$ is the weight of the insoluble bit after extraction with water.

\section{Solubility test}

The test was done by using a method described by JEFCA (Joint Expert Committee on Food Additives). The weight (W1) of a $70 \mathrm{~mm}$ glass fibre paper (pore size 1.2 micron) is determined followed by drying in an oven at $105{ }^{\circ} \mathrm{C}$ for $1 \mathrm{~h}$ and subsequently cooled in a desiccator containing silica gel.

The suspension of the test material, 1-2 weight\% (S) was prepared in $\mathrm{ddH}_{2} \mathrm{O}$ followed by hydration for $12 \mathrm{~h}$ at $25{ }^{\circ} \mathrm{C}$. The hydrated scattering is then centrifuged for 2-5 min at 10,000 Revolution per Minute (RPM) and filtered. The filtrate was dried at $105^{\circ} \mathrm{C}$ for $6 \mathrm{~h}$ and cooled to a constant weight (W2) Insoluble amount was calculated as:

The solubility test utilised a technique endorsed by JEFCA (Joint Expert Committee on Food Additives). The weight (W1) of a $70 \mathrm{~mm}$ glass fibre paper (pore estimate 1.2 microns) is resolved trailed by drying in a broiler at $105^{\circ} \mathrm{C}$ for $1 \mathrm{~h}$ and along these lines cooled in a desiccator containing silica gel.

The suspension of the test material, 1-2 weight \% (S) was incubated in $\mathrm{ddH}_{2} \mathrm{O}$ took after by hydration for $12 \mathrm{~h}$ at $25^{\circ} \mathrm{C}$. The hydrated scattering is then centrifuged for 2-5 min at 10,000 Revolution per Minute (RPM) and filtered. The filtrate was dried at $105^{\circ} \mathrm{C}$ for $6 \mathrm{~h}$ and cooled to a consistent weight (W2). The insoluble amount was figured as:

$$
\% \text { Hydrogel }=\left(\frac{\mathrm{W} 2-\mathrm{W} 1}{\mathrm{~S}}\right) * 100
$$

\section{Scanning electron microscopy (SEM)}

SEM was used to determine the surface geography and natural creation of the hydrogels. Amplification in SEM was controlled up to 6 orders of magnitude from 10 to 500,000 times [17-20]. The hydrogel was gently rinsed with $\mathrm{ddH}_{2} \mathrm{O}$ and dried at $37^{\circ} \mathrm{C}$ for $24 \mathrm{~h}$. The swollen thick film was obtained after immersion of the hydrogel disks in $\mathrm{ddH}_{2} \mathrm{O}$ for $15 \mathrm{~min}$. The samples were also freeze-dried and stored at $40{ }^{\circ} \mathrm{C}$ for further use.

Chemical characterization of PVA/PVP hydrogels and hybrids by Fourier transform infrared spectroscopy (FTIR)

FTIR was utilised to examine the nearness of particular chemical functional groups of in the samples [21,22]. FTIR spectra were obtained in the range of wave number from 4000 to $700 \mathrm{~cm}^{-1}$ (Paragon 1000, Perkin-Elmer, USA). The FTIR spectra were normalised and major vibration bands were associated with chemical groups.

\section{X-ray diffraction (XRD)}

XRD analysis was performed to analyze the crystallinity index of the hydrogels. XRD tosses light on the properties of the distinctive stages (for instance basic make-up, \% crystallinity and crystallite measurement, introduction and strains) exhibit in the polymer/polymer mix lattice. The semi-crystalline polymers were characterised by XRD [23]. The crystallinity index (CrI) of the samples was determined by the equation:

$$
\operatorname{CrI}(\%)=\mathrm{A}_{\text {Crystal }} / \mathrm{A}_{\text {Total }} \times 100
$$

Where, $A_{\text {crystal }}$ is the sum of the areas under the crystalline diffraction peaks and $A_{\text {Total }}$ represents the total area under the diffraction curve between $2 \theta=10^{\circ}-80^{\circ}$.

The properties, viz. mechanical and water take-up, of a polymer shift with the adjustment in "level of crystallinity" and is frequently spoken to as \% crystallinity or crystalline/nebulous proportion. The 
level of crystallinity is of tremendous significance in the polymer industry and can be dictated by XRD [24].

\section{Statistical analysis}

An analysis of the average and standard error was conducted on the data obtained in each of the experimental studies with statistical package Assistat version-7.4 beta 2010 for comparison of mean responses (mean standard error) and to determine the statistical significance. The standard deviation (SD) about the mean for each of the regimens was depicted in the figures.

\section{RESULTS AND DISCUSSION}

The hydrogel sheet formulations given in table 1 were prepared with keratin solution and polyethylene glycol, aloe vera gel, chitosan solution and honey were separately studied for their $\mathrm{pH}$, solubility and swelling capacities. The physicochemical properties of the hydrogel were studied by SEM, FTIR and XRD analysis systematically.

\section{pH test}

The $\mathrm{pH}$ estimation of each hydrogel preparation is given in table $2 . \mathrm{H}$ PEG hydrogel and A-PPG' were slightly acidic in comparison to other hydrogels. This could be ascribed to the acidic nature of honey itself with $\mathrm{pH} \sim 3.2$ and 4.5 [12]. Different hydrogels are in the range of 5.65.9 and slightly acidic. As indicated by [25] dressings with a slightly acidic $\mathrm{pH}$ ( $\mathrm{pH}$ of 5.5) are more acceptable to wear, and the low $\mathrm{pH}$ makes an unfavourable situation for bacterial development [26]. Besides, the acidic environment improved a most extreme arrival of oxygen to address the issues of the body's tissue repair [27]. In this manner, the hydrogels give an appropriate domain to the injured region as they have ideal levels of $\mathrm{pH}$. Hydrogel $\mathrm{C}$ was utilised as control which is an antacid in contrast with the defined hydrogels.

Table 2: pH value for each hydrogel

\begin{tabular}{lllll}
\hline Hydrogels & pH value & & \\
\cline { 2 - 4 } & $\mathbf{1}$ & $\mathbf{2}$ & $\mathbf{3}$ & \\
\hline C & 6.7 & 6.9 & 6.8 & Average \\
PPG hydrogel & 5.5 & 5.4 & 5.8 & 5.6 \\
H-PEG hydrogel & 4.5 & 4.8 & 4.2 & 6.1 \\
C-PEG hydrogel & 5.9 & 5.8 & 5.8 & 5.9 \\
A-PPG hydrogel & 6.1 & 5.7 & 5.9 & 4.9 \\
A-PPG' hydrogel & 4.9 & 4.8 & 5.0 & \\
\hline
\end{tabular}

Abbreviation: PPG, Polypropylene Glycol; PEG, Polyethylene Glycol; H-PEG, Honey+Polyethylene Glycol; C-PEG, Chitosan+PEG; A-PPG, Aloevera+PPG; A-PPG', Aloe-vera+PPG (last two are different in concentration).

\section{Swelling test}

The swelling percentage of each hydrogel can be seen in the fig. 1 . Overall, moderate swelling capacity can be seen in non-ionic hydrogels such as polyacrylamide (PAM) and PVA-based hydrogels [28]. PPG hydrogel showed high abilities in the absorbing liquid when contrasted with different hydrogels and swell much faster. PPG hydrogel comprises of keratin as primary parts in the hydrogels. Moreover, hydrogels with high absorbing capacities are suggested for exudative injuries, for example blazes [29]. Other hydrogels have many other components such as aloe-vera, chitosan and honey adding with the keratin which causes swelling percentage to be lesser than the PPG hydrogel.

A-PPG hydrogel has a swelling percentage of $34.7 \%$ contained aloevera and keratin only. C-PEG hydrogel possesses $29.9 \%$ swelling capacity. PPG hydrogel can be applied to severe wounds that exudate abundantly whilst other hydrogels should be considered before apply.

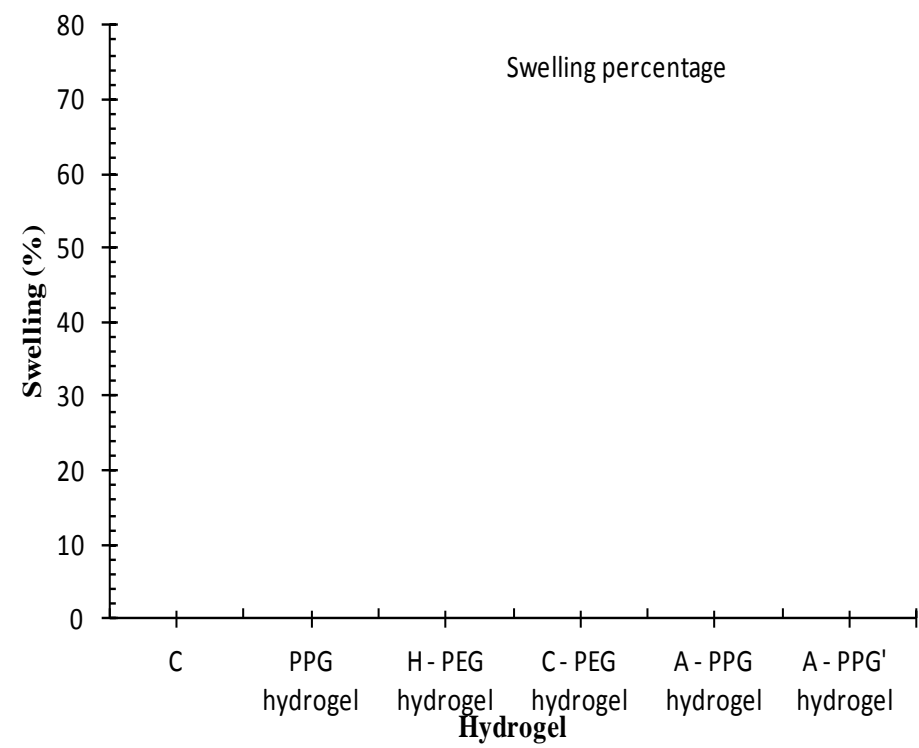

Fig. 1: Swelling percentage of hydrogels. All the experiments were carried out in triplicates $(n=3)$ for each sample and mean average values with standard error $( \pm S D)$ were calculated and represented in the error bars

Swelling capacity was increased with the hydrophilic polymers, ionic polymers containing monovalent ions, lower crosslink density and possesses hydrophilic crosslinkers. The composition of hydrogel seems to be more solvent, less salts, low ionic strength, less numbers 
of di and trivalent cations [30]. Hence, we can conclude that PPG hydrogel has low crosslink density which holds water molecules in between the cross-linkages for a long time. According to [31], keratin from chicken feather showed characteristics of hydrophobicity and low solubility. H-PEG hydrogel and A-PPG' hydrogel with honey, are hydrophobic in nature with less crosslinking network [32] cause the swelling capacity of the hydrogels to below. Chitosan in the C-PEG hydrogel donates its cationic characteristics to the anionic part of water, thus attracts the water. A-PPG hydrogel has desiccated form which may contribute for the better swelling capacity.

\section{Solubility test}

The solubility of hydrogel increases as the temperature of the medium increases [30]. All hydrogels showed fair solubility in the aqueous medium. Hence, it indicated that the hydrogels are soluble (fig. 2) which exudates and provides the required nutrients as well as a suitable environment for the wound healing.

A-PPG hydrogel which consists of $10 \%$ of aloe-vera and $30 \%$ of keratin has the highest solubility as compared to other hydrogels. Overall, the formulated hydrogels are highly soluble in nature.

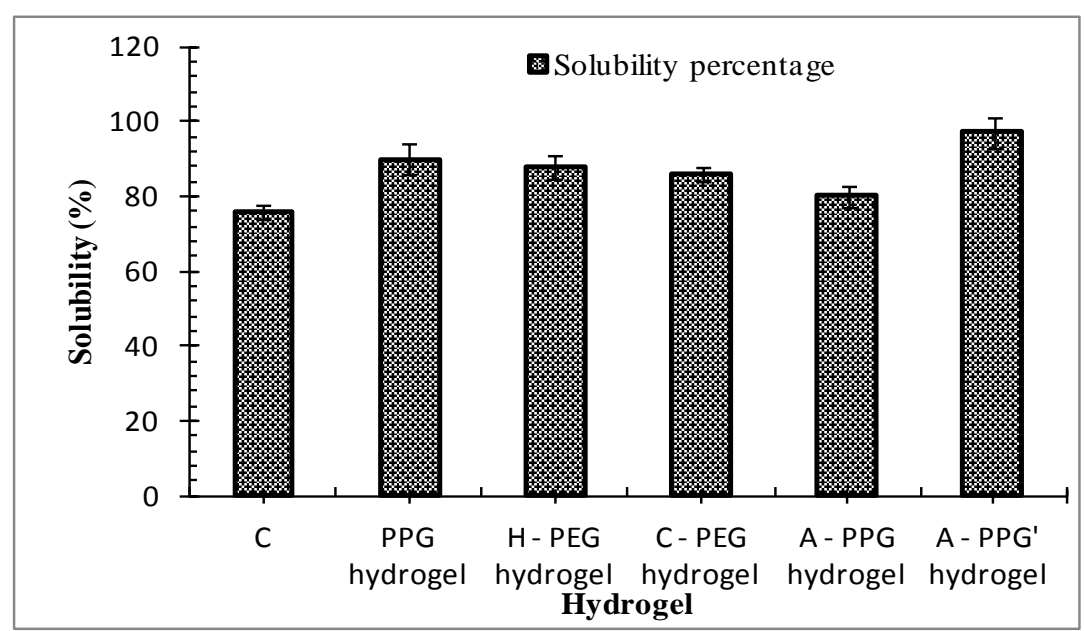

Fig. 2: Percentage of Solubility on hydrogels. All the experiments were carried out in triplicates $(n=3)$ for each sample and mean average values with standard error $( \pm S D)$ were calculated and represented in the error bars

\section{Scanning electron microscopy}

An average porous surface obtained from image analysis of SEM is shown in fig. 3. The data revealed that the PPG hydrogel has fine crystals-like network spread on the surface and the surface of C-PEG hydrogel is uneven and overlapping layers, the surface of A-PPG hydrogel appeared as desiccated form, the A-PPG' hydrogel is slightly uneven and less overlapping surface when compared with CPEG hydrogel. The surface of H-PEG hydrogel is porous and rough as compared to PPG hydrogel.

The average pore size was $1.42 \mu \mathrm{m}$ in the area of $274.32 \mu \mathrm{m}^{2}$. H-PEG hydrogel has a maximum porosity as compared to other hydrogels. In a previous study, hydrogel possesses very small pore size of 1-10 $\mathrm{nm}$ [33].
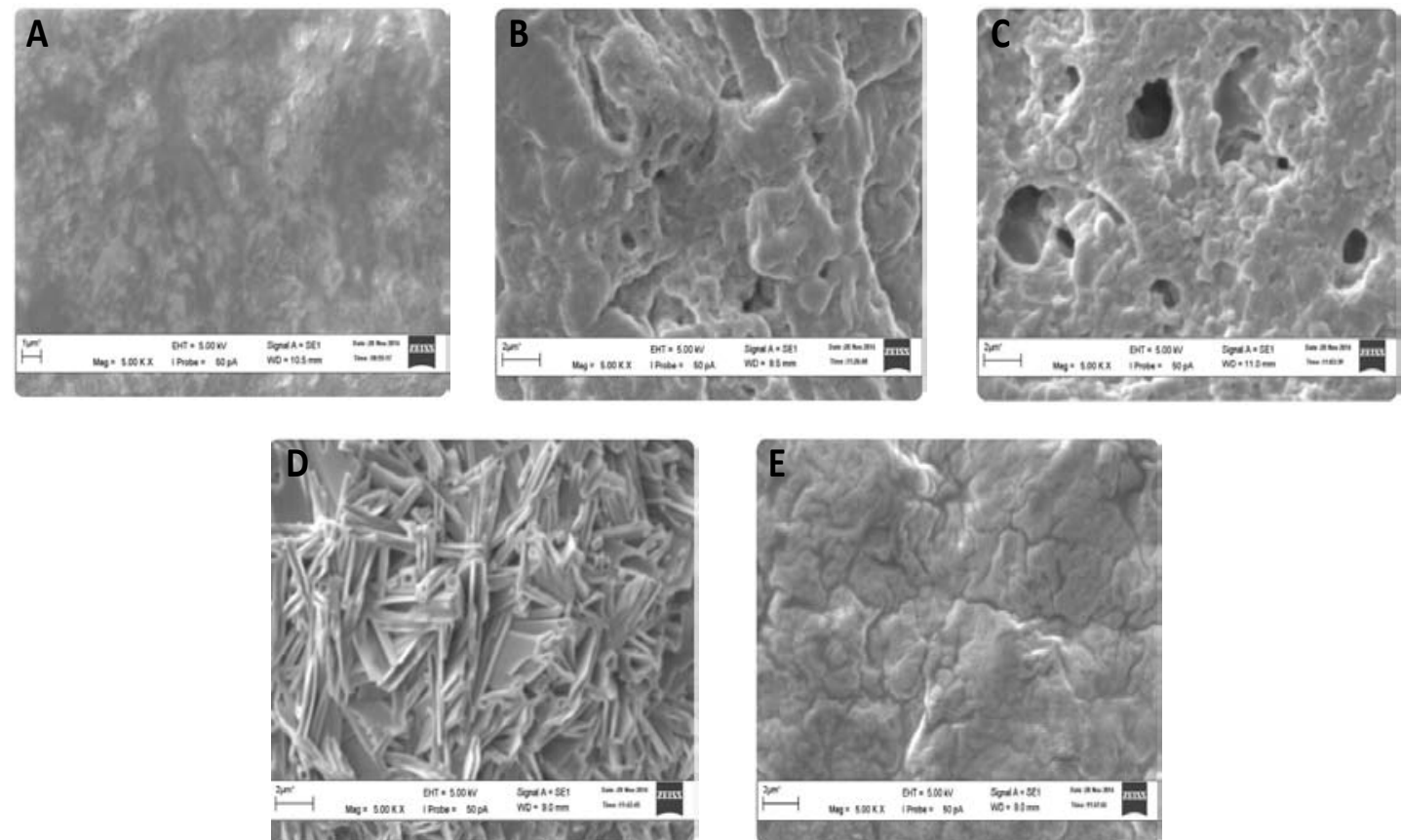

Fig. 3: Topography of hydrogel at magnification of 5000x A) PPG hydrogel B) H-PEG hydrogel C) C-PEG hydrogel D) A-PPG hydrogel E) APPG' hydrogel 


\section{FTIR analysis}

From FTIR spectroscopy all hydrogels demonstrated the presence of $-\mathrm{OH} .-\mathrm{CH} 2=\mathrm{CH},-\mathrm{NH} 2,-\mathrm{COOH}$ and $-\mathrm{NO}_{2}$ functional groups and have shown absorption band estimation as given in Fig.4. It demonstrated the stretching of ether groups [34-36, 37] from 1050-1150 $\mathrm{cm}^{-1}$. Alkyl $\left(\mathrm{R}-\mathrm{CH}_{2}\right)$ stretching mode from $2900-3000 \mathrm{~cm}^{-1}$ were watched (37). The commitment of hydroxyl groups was inspected with a range from $3200-3400 \mathrm{~cm}^{-1}$. The nearness of hydrophilic and hydrophobic moieties which was checked by FTIR makes them soluble in both aqueous and organic medium. This made it imperative for medication framework [35]. The vibration bands from $900-950 \mathrm{~cm}^{-1}$ ascribed to alcohol. The alternate groups present is given in table 3 . The presence of more- $\mathrm{OH}$ gatherings contributed in hydrogen bonding in the hydrogels. A more extensive band of the hydroxyl group was the after effect of sol-gel responses. Utilitarian groups of amines and nitro speaks to the attributes of keratin [38]. HPEG hydrogel has more hydrogen bonding contrasted with others and reasonable for topical application. Thus, FTIR spectra demonstrated chemical groups which are present in the complex polymeric hydrogel.
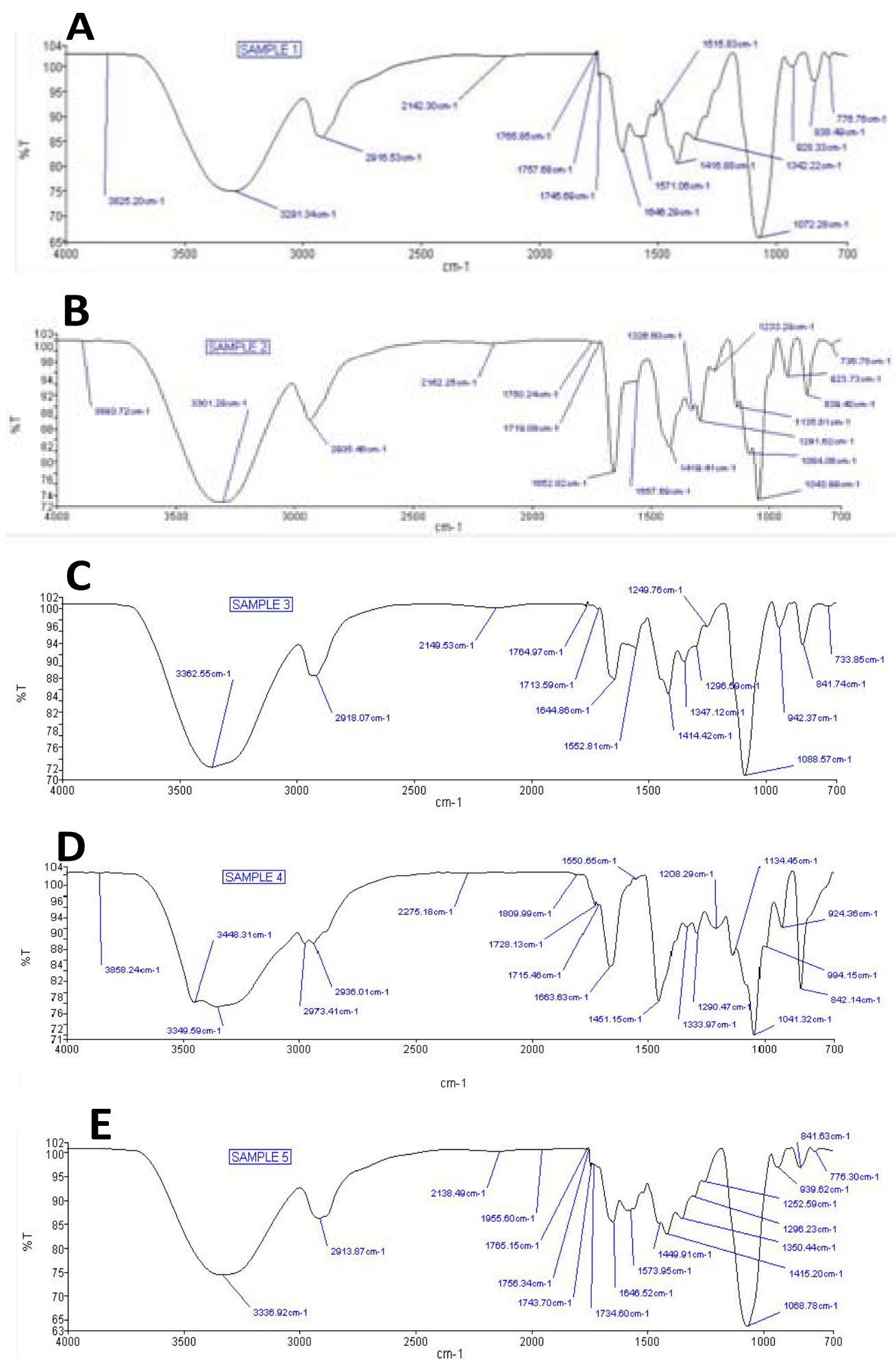

Fig. 4: IR Absorbance A) PPG hydrogel B) H-PEG hydrogel C) C-PEG hydrogel D) A-PPG hydrogel E) A-PPG' hydrogel 
Table 3: Results of IR absorptions of hydrogels

\begin{tabular}{llll}
\hline S. No. & Absorption range & Specific type of bond & Functional group \\
\hline 1. & $3300-3400$ & O-H stretch & Alcohols \\
2. & $2800-2950$ & C-H stretch & Alkanes \\
3. & $2100-2270$ & $\mathrm{C}=\mathrm{C}$ & Alkynes \\
4. & $1750-1735$ & $\mathrm{C}=\mathrm{O}$ stretch & Esters \\
5. & $1700-1730$ & $\mathrm{C}=\mathrm{O}$ stretch & Carboxylic Acid \\
6. & $1640-1500$ & $\mathrm{~N}-\mathrm{H}$ bend & Amines \\
7. & $1640-1501$ & $\mathrm{~N}-\mathrm{H}$ bend & Amines \\
8. & $1400-1440$ & $\mathrm{O}-\mathrm{H}$ bend & Carboxylic Acid \\
9. & $1300-1390$ & - - NO2 (aliphatic) & Nitro Group \\
10. & $1000-1260$ & $\mathrm{C}-\mathrm{O}$ stretch & Alcohols \\
11. & $1000-1260$ & $\mathrm{C}-\mathrm{O}$ stretch & Alcohols \\
12. & $1000-1260$ & $\mathrm{C}-\mathrm{O}$ stretch & Alcohols \\
13. & $1000-1261$ & $\mathrm{C}-\mathrm{O}$ stretch & Alcohols \\
14. & $1000-1262$ & $\mathrm{C}-\mathrm{O}$ stretch & Alcohols \\
15. & $900-950$ & $-\mathrm{OH}$ & Alcohols \\
16. & $900-650$ & $\mathrm{~N}-\mathrm{H}$ bend & Amines \\
17. & $770-730$ & $\mathrm{C}-\mathrm{H}$ stretch & Alkanes \\
\hline
\end{tabular}

All the experiments were carried out in triplicates $(n=3)$ for each sample and mean average values with standard error $( \pm$ SD) were calculated.

\section{X-ray diffraction}

XRD analysis was performed to analyze the crystallinity index of the hydrogels. From the table 4 , the maximum crystallinity was observed in PPG hydrogel and A-PPG hydrogel as compared to other hydrogels. Whilst, H-PEG hydrogel and C-PEG hydrogel have crystallinity within $32-35 \%$ over a total area of the hydrogel as shown in fig. 5. Overall, the hydrogels are semi-crystalline and amorphous in nature [39].
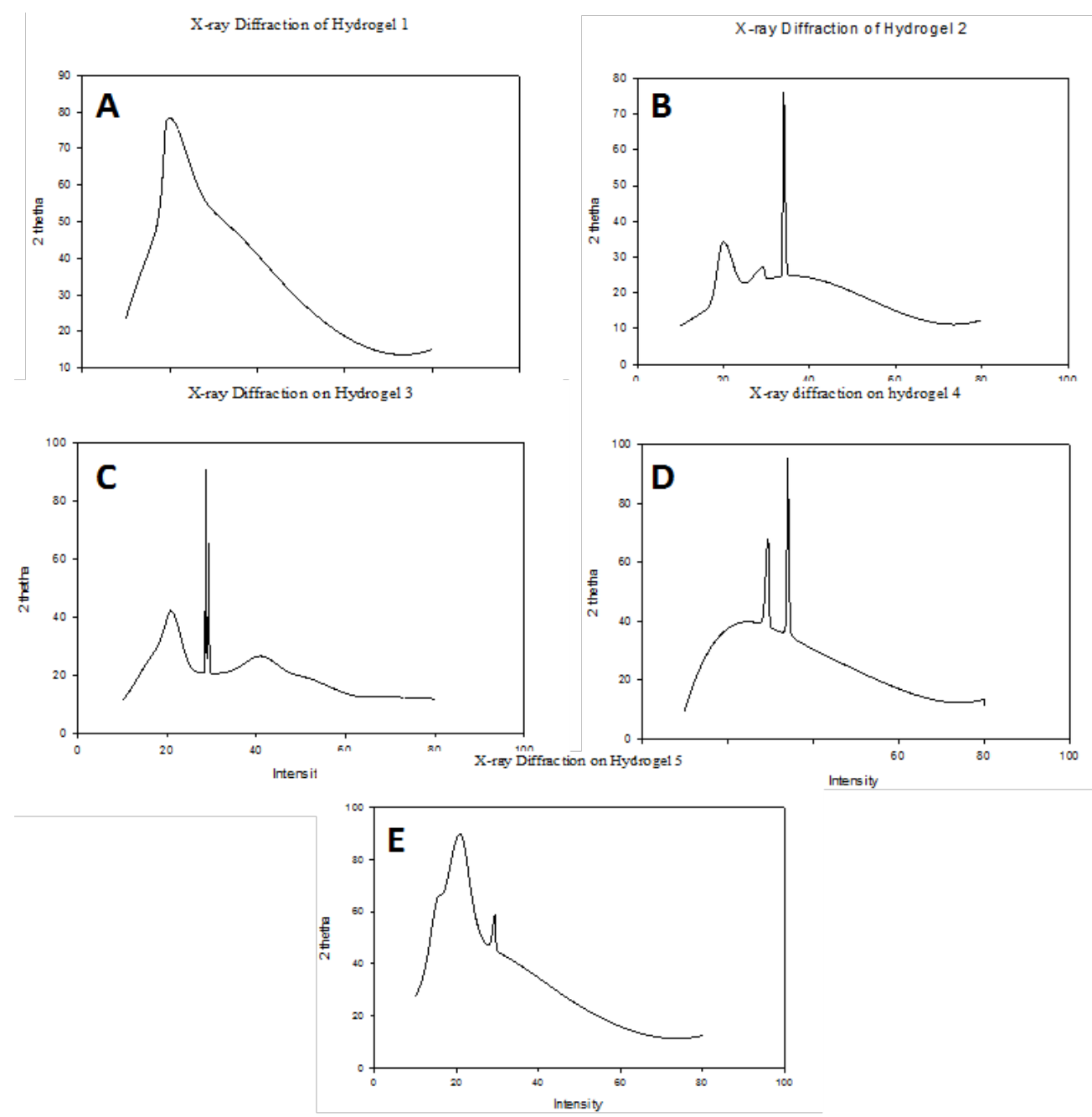

Fig. 5: X-ray diffraction studies of the keratin based hydrogels A) PPG hydrogel B) H-PEG hydrogel C) C-PEG hydrogel D) A-PPG hydrogel E) A-PPG' hydrogel 
Table 4: Crystallinity index of Hydrogels

\begin{tabular}{lll}
\hline Hydrogels & Crystallinity index (\%) & Crystalline/Amorphous ratio \\
\hline PPG hydrogel & $46 \%$ & $23: 27$ \\
H-PEG hydrogel & $35 \%$ & $7: 13$ \\
C-PEG hydrogel & $32 \%$ & $8: 17$ \\
A-PPG hydrogel & $47 \%$ & $47: 53$ \\
A-PPG' hydrogel & $45 \%$ & $9: 11$ \\
\hline
\end{tabular}

Abbreviation: PPG, Polypropylene Glycol; PEG, Polyethylene Glycol; H-PEG, Honey+Polyethylene Glycol; C-PEG, Chitosan+PEG; A-PPG, Aloevera+PPG; A-PPG', Aloe-vera+PPG (last two are different in concentration).

The hydrogels were formulated by using PVA solution, where it can be cross-linked through the use of bi functional cross-linking agents [40]. In this formulation, PEG and PPG were used. The crystallinity was found to increase with increasing the freezing time and PVA solution concentration [41]. The response of the materials to wound exudates and the biochemical environment provided by a keratin protein becomes very essential in the healing process. An optimum wound dressing protects the injured tissue, maintains a moist environment, water permeability, maintains microbial control, delivers healing agents to the wound, easy to apply, does not require frequent dressings and non-toxic and non-antigenic [42]. Addition with healing agents, the wound healing gel showed effective healing results on the wound.

\section{CONCLUSION}

It was observed that the combination of chitosan, honey and aloe vera has changed the properties of hydrogel network. Keratin hydrogel showed excellent physical properties, e.g., adequate transparency, ease to apply, capacity to retain exudates, and also slightly acidic $\mathrm{pH}$, which fulfil the vital necessities of an injury dressing. Swelling analysis showed that the PPG hydrogen has a low crosslink density, which holds water molecules in between the cross-linkages for a long time. It was observed that all hydrogels showed fair solubility in the aqueous medium. The keratin was found to be effective as a crosslinking agent for the preparation of hydrogel. The optimum concentration of keratin $(30 \%)$ considered as good active ingredient (API) for the consumer. The biomaterial manipulated by means of chemical treatments and natural products seems to be very useful for the synthesis of the medicinal product of mankind usage. These treatment results indicated promising recovery and treatment of wounds without any side effect which boosts up the herbal health care products. Thus, keratin-based hydrogel is a profitable way to deal dermal injury more research is required to commercialize its application in the biomedical field.

\section{CONFLICT OF INTERESTS}

Declared none

\section{ACKNOWLEDGEMENTS}

Author are thankful to University Malaysia Pahang (UMP) for proving facilities and financial support for conducting this research.

\section{REFERENCES}

1. Mishra RK, Banthia AK, Majeed ABA. Pectin based formulations for biomedical applications: a review. Asian J Pharm Clin Res 2012;5:1-7.

2. Maziad NA, El-hamouly S, Zied E, El-Kelani TA, Nasef NR. Radiation preparation of smart hydrogel has antimicrobial properties for controlled release of ciprofloxacin in drug delivery systems. Asian J Pharm Clin Res 2015;8:193-200.

3. Sharma S, Gupta A. Sustainable management of keratin waste biomass: applications and future perspectives. Braz Arch Biol Technol 2016;59. http://dx.doi.org/10.1590/1678-43242016150684

4. Nagam SP, Jyothi AN, Poojitha J, Aruna S, Nadendla RR. A comprehensive review on hydrogels. Int J Chem Pharm Res 2016;8:19-23.

5. Moll R, Divo M, Langbein L. The human keratins: biology and pathology. Histochem Cell Biol 2008;129:705-33.
6. Baranoski S, Ayello EA. Wound care essentials: practice principles: Lippincott Williams and Wilkins; 2008.

7. Kerstein MD. The scientific basis of healing. Adv Skin Wound Care 1997;10:30-6.

8. Katoh K, Shibayama M, Tanabe T, Yamauchi K. Preparation and properties of keratin-poly (vinyl alcohol) blend fiber. J Appl Polym Sci 2004;91:756-62.

9. Barone JR. Lignocellulosic fiber-reinforced keratin polymer composites. J Polym Environ 2009;17:143-51.

10. Wang T, Zhu XK, Xue XT, Wu DY. Hydrogel sheets of chitosan, honey and gelatin as burn wound dressings. Carbohydr Polym 2012;88:75-83.

11. Şenel S, McClure SJ. Potential applications of chitosan in veterinary medicine. Adv Drug Delivery Rev 2004;56:1467-80.

12. Molan PC. The role of honey in the management of wounds. J Wound Care 1999;8:415-8.

13. Viswanathan V, Kesavan R, Kavitha K, Kumpatla S. A pilot study on the effects of a polyherbal formulation cream on diabetic foot ulcers. Indian J Med Res 2011;134:168.

14. Gupta A, Perumal R. Process for extracting keratin. Google Patents US 20120130048 A1; 2013.

15. Gupta A, Kamarudin NB, Kee CYG, Yunus RBM. Extraction of keratin protein from the chicken feather. J Chem Chem Eng 2012;6:732

16. Katayama T, Nakauma M, Todoriki S, Phillips GO, Tada M. Radiation-induced polymerization of gum arabic (Acacia senegal) in aqueous solution. Food Hydrocoll 2006;20:983-9.

17. Aikawa K, Matsumoto K, Uda H, Tanaka S, Shimamura $\mathrm{H}_{\text {, }}$ Aramaki $\mathrm{Y}$, et al. Hydrogel formation of the $\mathrm{pH}$ response polymer polyvinyl acetal diethylamino acetate (AEA). Int J Pharm 1998;167:97-104.

18. Aouada FA, de Moura MR, Fernandes PR, Rubira AF, Muniz EC. Optical and morphological characterization of polyacrylamide hydrogel and liquid crystal systems. Eur Polym J 2005;41:2134-41.

19. El Fray M, Pilaszkiewicz A, Swieszkowski W, Kurzydlowski KJ. Morphological assessment of chemically modified restructured poly (vinyl alcohol) hydrogel. Eur Polym J 2007;43:2035-40.

20. Pourjavadi A, Kurdtabar M. Collagen-based highly porous hydrogel without any porogen: Synthesis and characteristics. Eur Polym J 2007;43:877-89.

21. Mansur HS, Oréfice RL, Mansur AA. Characterization of poly (vinyl alcohol)/poly (ethylene glycol) hydrogels and PVAderived hybrids by small-angle X-ray scattering and FTIR spectroscopy. Polymer 2004;45:7193-202.

22. Torres R, Usall J, Teixido N, Abadias M, Vinas I. Liquid formulation of the biocontrol agent Candida sake by modifying water activity or adding protectants. J Appl Microbiol 2003;94:330-9.

23. Hench LL, Jones JR. Biomaterials, artificial organs and tissue engineering. Woodhead Publishing Limited and CRC Press LLC: Cambridge, England and Boca Raton, FL, USA; 2005.

24. Pal K, Banthia A, Majumdar D. Polymeric hydrogels: characterization and biomedical applications. Des Monomers Polym 2009;12:197-220.

25. Parsons D, Bowler PG, Myles V, Jones S. Silver antimicrobial dressings in wound management: a comparison of antibacterial, physical, and chemical characteristics. Wounds 2005; 17:222-32.

26. Molan P. Establishing honey as a recognised medicine. J Am Apitherapy Soc 2000; 7:7-9. 
27. Mao N, Russell S. Nonwoven wound dressings. Textile Progress 2004;36:1-57.

28. Lozinsky V, Solodova E, Zubov A, Simenel I. Study of cryo structuration of polymer systems. XI. The formation of PVA cryogels by freezing-thawing the polymer aqueous solutions containing additives of some polyols. J Appl Polym Sci 1995;58:171-7.

29. Kokabi M, Sirousazar M, Hassan ZM. PVA-clay nanocomposite hydrogels for wound dressing. Eur Polym J 2007;43:773-81.

30. Singh A, Hosseini M, Hariprasad SM. Polyethylene glycol hydrogel polymer sealant for the closure of sutureless sclerotomies: a histologic study. Am J Ophthalmol 2010;150:346-51. e2.

31. Martínez-Hernández AL, Velasco-Santos C. Keratin fibres from chicken feathers: structure and advances in polymer composites. Keratin: Structure, Properties and Applications; 2012. p. 149-211.

32. Mohd Zohdi R, Bakar A, Zakaria MZ, Mohamed Mustapha N, Yusof N, Abdullah NH. The effect of topical application of Malaysian honey on burn wound healing. J Vet Med 2004;16:47-50.

33. Yoldas BE. Alumina gels that form porous transparent Al203. J Mater Sci 1975;10:1856-60.

34. Sahlin JJ, Peppas NA. Near-field FTIR imaging: a technique for enhancing spatial resolution in FTIR microscopy. J Appl Polym Sci 1997;63:103-10.
35. Roberts MJ, Bentley MD, Harris JM. Chemistry for peptide and protein PEGylation. Adv Drug Delivery Rev 2012;64:116-27.

36. Singh TJ, Bhat SV. Morphology and conductivity studies of a new solid polymer electrolyte: (PEG) xLiClO4. Bull Mater Sci 2003;26:707-14.

37. Coates J. In: Meyers RA. editor. Encyclopaedia of analytical chemistry. Chichester: Wiley; 2000. p. 10815-37.

38. Rouse JG, Van Dyke ME. A review of keratin-based biomaterials for biomedical applications. Materials 2010;3:999-1014.

39. Ding F, Shi X, Li X, Cai J, Duan B, Du Y. Homogeneous synthesis and characterization of quaternized chitin in $\mathrm{NaOH} /$ urea aqueous solution. Carbohydr Polym 2012;87:422-6.

40. Peppas NA. Hydrogels in medicine and pharmacy: properties and applications: CRC PressI Llc; 1987.

41. Berghmans H, Stoks W. Thermoreversible gelation of vinyl polymers. In: Kleintjens LA, Lemstra PJ. editors. Integration of fundamental polymer science and technology. Dordrecht: Springer Netherlands; 1986. p. 218-29.

42. Boateng JS, Matthews KH, Stevens HN, Eccleston GM. Wound healing dressings and drug delivery systems: a review. J Pharm Sci 2008;97:2892-923.

\section{How to cite this article}

- Priyaah Kumaran, Arun Gupta, Swati Sharma. Synthesis of wound-healing keratin hydrogels using chicken feathers proteins and its properties. Int J Pharm Pharm Sci 2017;9(2):171-178 